M.A. Aleksandra Hoffmann-Wróblewska*, https:// orcid.org/0000-0003-0546-208X

M.A. Karolina Janik*, https:// orcid.org/0000-0002-5530-0778

M.A. Anastazja Zawiślak*, https:// orcid.org/0000-0001-5513-3036

Catholic University

of Lublin

\title{
Internet and its role in selected aspects of everyday life of adolescents
}

\author{
Internet $\mathrm{i}$ jego rola $w$ wybranych aspektach \\ życia codziennego adolescentów ${ }^{1}$
}

\author{
https://doi.org/10.34766/fetr.v46i2.770
}

\begin{abstract}
The purpose of this article is to present the issue of the Internet in the everyday lives of young people. The article is a review and synthesis of the findings of ten years of research on young people's use of the Internet. This article also provides an overview of research conducted primarily in foreign research institutions. The query was based on scientific databases available online (EBSCO, Google Scholar). According to several studies, young people mostly use social media to portray themselves to the rest of the world. They use social media to share images and information about their lives. Teenagers, in particular, are constantly engaging with others online for entertainment as well as to broaden their knowledge and obtain education. One of the most critical aspects of functioning in cyberspace is one's public image on social media.
\end{abstract}

Keywords: adolescence, communication, youth, social media, image

Abstrakt: Celem artykułu jest przybliżenie zagadnienia Internetu w życiu codziennym młodzieży. Artykuł ma charakter przeglądowy i stanowi syntezę wyników badań przeprowadzonych na przestrzeni ostatnich 10 lat $\mathrm{w}$ zakresie użytkowania Internetu przez adolescentów. Jest to przegląd dotyczący badań przeprowadzonych głównie w zagranicznych ośrodkach naukowych. Kwerendy dokonano za pomocą internetowych baz naukowych (EBSCO, Google Scholar). Z badań wynika, że młodzież korzysta $\mathrm{z}$ mediów społecznościowych głównie do autoprezentacji. $\mathrm{W}$ ten sposób reprezentują się w świecie. Publikują zdjęcia i dzielą się aspektami swojego życia. W szczególności w dzisiejszych czasach nastolatkowie używają coraz większej liczby narzędzi online do komunikowania się z innymi ludźmi, w celu rozrywki, ale również poszerzania wiedzy i edukacji, a wizerunek $\mathrm{w}$ mediach społecznościowych stanowi jeden $\mathrm{z}$ najistotniejszych elementów funkcjonowania w sieci.

Słowa kluczowe: adolescencja, komunikacja, młodzież, socialmedia, wizerunek

\section{Introduction}

Online social networks have changed the way people communicate and interact over the last decade. The positive effect of social networks on self-esteem has been found to be

\footnotetext{
${ }^{1}$ Wersja w języku polskim na stronie:

https://www.stowarzyszeniefidesetratio.pl/Presentations0/2021-2-03Hoff2.pdf
} 
inconsistent in many studies (Pantic, 2014). The aim of this article is to introduce the subject of the Internet in the lives of young people. The article is a review, thus it examines publications on the Internet's role in various aspects of adolescent everyday life. According to study conducted in 2018, the number of teenagers who use the Internet at home rose by $29 \%$ as compared to studies conducted 14 years ago. Adolescents aged 6 to 12 years spend an average of 14 hours a week on the Internet, according to parental or guardian statements and findings. Adolescents aged 13 to 15 use the Internet for 7 hours longer than those in the previous age group. Furthermore, adolescents aged 16 to 19 years use the Internet even more often - for a total of 28 hours per week. The Internet is used by $95 \%$ of American adolescents, and $74 \%$ of them use it mostly on mobile devices (Purcell, 2013). This phenomenon is primarily influenced by the wide availability of electronic devices. Adolescents mainly equate the network with a space for entertainment, access to culture, and a center of social life understood as an opportunity to create their own image or search for identity. The argument is supported by the most recent figures, which show that people are using social networking sites to communicate with friends and family through various instant messengers and chats (61\%). Such activities as watching movies and TV series $(62 \%)$, listening to music $(65 \%)$, playing online games (40\%), doing homework (50\%), expanding knowledge in the areas of interest $(37 \%)$ have all been migrated to the web (Bochenek \& Lange, 2019). According to the most recent studies, there is a fairly clear division in how young people use the Internet. At the top of the list are communication, image creation, as well as entertainment and education. The level of self-esteem and social adaptation is directly related to the online image that is formed during adolescence. The Internet allows young people to explore their own identities and strengthen interpersonal relations (Valkenburg \& Peter, 2011). Teenagers interact and present themselves using a growing number of online resources. The image in social media is an integral part of how the network works, as it has evolved into a place where teens can get social support. This encourages users to keep creating and managing their own online image. The Internet itself has become a tool for creating an image in a controlled manner, but it is also associated with being judged by the Internet community. As a result, the issue of whether it is harmful or uplifting for those who are only entering adulthood arises.

\section{The effect of social media on young people in the context of self-presentation and creating their own image}

Throughout the years, observations have been made about how the Internet has developed into a medium, whose growth and potential are used mostly by young people. The social network is considered as an essential component of young people's lives and constitutes a source of everyday social interaction, education, and entertainment (Bochenek 
\& Lange, 2019). Both online and offline, people use various forms of self-presentation to communicate with strangers, colleagues, relatives and friends. Instant messaging, which incorporates a graphical representation of people known as friends icons, is one of the many ways to connect over the Internet. According to Goffman's self-presentation theory, the Internet is viewed as a framework in which individuals are able to control their image. The author provides a broad overview of how people portray themselves and speaks about the elements of their online identity (Rodgers, Melioli, et al., 2013). Every social interaction, according to the theory's author, is compared to a performance that aims to make an acceptable impression on the audience. It is also related to maintaining control over the reactions that occur in the recipients of specific actions that are performed by the individual. During the process of shaping an image on the Internet, this type of activity may be detected. The Internet also helps to search for information about the people with whom we communicate. This allows them to predict various behaviors and choose a self-presentation style that will elicit a particular response (Nowak \& Gomes, 2014). The researchers conducted a study to investigate the Internet's effect on personality, personal autonomy, and real-life relationships. As concluded, the Internet allows teenagers to develop their own interests, identify with others and, simultaneously, set themselves apart from others (Borca, Bina, Keller et al., 2015). The key factor in the creation of a young person's identity is selfpresentation, which involves both personal and virtual contexts (Yang \& Brown, 2016). Members of Facebook need to create their own online profile, which incorporates personal details, physical appearance, individual tastes, and preferences. Users eventually create and maintain their image as a result of these functions. A large amount of data allows for a thorough self-presentation to emphasize certain aspects of one's "real" self (Haferkamp \& Krämer, 2011). Parents commonly believe that the intensity of using social networks is the main determinant, or even constitutes the only risk factor for negative consequences. Although, in fact, an important role in the development of these consequences play psychopathological symptoms (Oberst, Wegmann, Stodt, Brand \& Chamarro, 2017). Increased "exposure to appearance" on the Internet is linked to increased body image disruption in teenage girls. Increased attention to beauty is significantly associated with weight dissatisfaction, striving for slenderness, thin-ideal internalization and selfobjectification (Meier \& Gray, 2014).

People are extremely motivated to use this new arena to present themselves. Such a tendency may result from everyone's innate desire to present themselves favorably in order to receive acceptance from others (Haferkamp \& Krämer, 2010). Young people use social media for self-presentation. They post photos and share different moments from their lives on social media (Uhls, Ellison \& Subrahmanyam, 2017). Young people use screen devices to stay connected not only to each other but also to the digital landscape. Unlimited access to the virtual world, and consequently, a variety of activities available especially since 
the introduction of mobile technology, has raised questions about the impact of this changing media environment on the mental health of young people. It quickly becomes obvious that the necessity to create one's own image on the Internet has introduced many changes to the real life of young people. The Internet has evolved into a place where teenagers can practice and grow autonomy (Borca, Bina, Keller et al., 2015) The question is, are these changes good or bad? The increased number of social networks boosts self-esteem and "belongingness", which can affect one's sense of well-being (Best et al., 2014). However, there is also a possibility that social support performed online may give a false sense of safety. What is more, a sense of belonging may also turn out to be apparent, and consequently fleeting. The study also challenges the opinion that social media enables different forms of social interaction and creative production that benefit the youth in general (Ekström, Olsson \& Shehata, 2014). On the other hand, researchers present evidence confirming that direct emotional support, based on empathy gained via the Internet, can help people overcome social barriers, such as the difficulty of making new friends (Anderson, Steen \& Stavropoulos, 2017).

Young people now use social media to keep track of how many people have seen their content. Owing to this pattern, they tend to control how they are perceived by other people, who they are and how they behave. The use of social media is associated with concerns about body image, which can lead to a deterioration in adolescent mental health (Uhls, Ellison \& Subrahmanyam, 2017). These findings suggest that adolescents who use social media frequently and whose content is mostly composed of images, may face increased body image concerns and struggle with psychological adaptation (Marengo et al., 2018). The Internet is a powerful socio-cultural medium that has an impact on the body image of adolescents, especially girls (Tiggemann, 2013). On the basis of conducted research concerning the correlation between Facebook users and the importance of body image, it is stated that those who use Facebook daily, achieve substantially higher scores than non-users. Time spent on the Internet seems to be considerably related to ideal internalization, and consequently to continuous supervision of body image and the pursuit of the ideal. According to research, provided images have a significant impact on adolescents' perceptions of the "perfect body shape" (Mulgrew, Volcevski-Kostas \& Rendell, 2014). Boys who watch videos of muscular men are less satisfied with their overall appearance as well as the shape of their upper body. It also relates to their sense of happiness and the development of more negative feelings. Their perceptions were contrasted to those who watch videos of musical celebrities and participants of TV shows who had an average appearance. On the other hand, teenagers who use social networking sites repleted with visual content are more dissatisfied with their bodies (Vries, Peter \& Graaf, 2016).

While social media appearance is linked to a cognitive interest in people's physical characteristics, studies have shown no substantial differences in girls' and boys' perceptions. 
However, there was a strong link discovered between body image, social pressure, and the use of intoxicants. General dissatisfaction with physical appearance translates into maintaining close relationships with peers and a stronger proclivity to drink alcohol solely for the purpose of getting drunk. Friendships that were slightly more distant were associated with a higher risk of smoking (Palmqvist \& Santavirta, 2011). The role of using social networking sites by teenagers is also related to their sexual development. Differences in the understanding of one's image in the field of sexuality were also observed between members of different genders. Teenagers' attitudes toward sexual content may have little bearing on how they view themselves on social networking sites. The sexual attitudes and behaviors of adolescents, especially among young teenagers, motivate the exposure of their own images with sexual content (Oosten, Peter \& Boot, 2015). The only noticeable difference is perceived in the girls' and boys' greater attention to details, including gender-based appearance (Trekels, Karsay, Eggermont \& Vandenbosch, 2018). Girls describe themselves in greater detail than boys, and their avatars are often more sexually explicit (Villani, Gatti, Confalonieri \& Riva, 2012). This kind of exploration can help adolescents discover different aspects of maturing and still developing self. Adolescents, who regularly share their lives online, have a better capacity to clearly and consistently understand themselves. Therefore, social media can play the role of the platform which enables practicing identity development skills, such as self-presentation and self-disclosure. Real-time presentation of teenagers online can also help to alleviate depression by increasing social support (Xie, Wang, Zhao, Lei, Niu \& Wang, 2018). However, the risk of negative incentives being amplified as a result of common online bullying should be addressed. Disapproval expressed in significant amount on social media is linked to more depressive symptoms than conventional bullying. One of the possible reasons for this conjuncture could be the fact that web posts are often public and stay forever in the online space. Self-presentation online can be extremely risky, as it increases the possibility of negative feedback on social media (Uhls, Ellison \& Subrahmanyam, 2017). The assessment of body image during the period of transition between childhood and adulthood is crucial for the growth of self-esteem and social value. The reaction of the Internet community as a group turns out to be as important as internal communication. Any teenager's daily life revolves around sending and receiving text messages and pictures. This practice is often used as a means of seeking acceptance and support from others.

\section{Internet networking as a means of communication between young people}

In today's world, the Internet is a valuable resource. Finding knowledge, doing online shopping, and communicating with people from all over the world are all possible in the virtual world. The popularity of social networking services (SNS) like Facebook, as well as 
other communication apps like Instagram, Twitter, and WhatsApp, is fueled by easy access to the Internet and the use of smartphones (Wu et al., 2013). The Internet can also be beneficial for young people and help them to carry out appropriate development tasks. The majority of the research has focused on the influence of the Internet on the formation of identity, social relations with peers, and romantic relationships (Best, Manktelow \& Taylor, 2014). Online-based communication has many advantages and is used by teenagers on a daily basis. The Internet can also be crucial in forming close relationships with peers and finding a common ground with parents (Borca, Bina, Keller et al., 2015). Nevertheless, the number of people using online communication tools is constantly growing in direct proportion to the negative impact of this type of communication (Wegmann \& Brand, 2016). It turns out that $68 \%$ of American teenagers use the Internet primarily to communicate with others (Purcell, 2013). During the maturation phase, both girls and boys use online contact to get to know each other and also to experiment with themselves (Vanden Abeele, 2015). Teenagers claim that the Internet allows them to discover their own identities and deepen relationships (Valkenburg \& Peter, 2011). A group of adolescents with attention deficit hyperactivity disorder (ADHD) who were diagnosed as children, use the Internet to meet new people. What is more, studies show that young women with ADHD prefer online interactions with strangers rather than direct contact. It can be originated from the fact that children with ADHD tend to make less real-life friendships (Mikami et al., 2015). According to previous studies (Tzavela et al., 2015; Valkenburg \& Peter, 2009), the majority of the research group's participants expressed opinions on the role of the Internet in the process of creating close relationships with peers. They stated that the use of the Internet is mainly restricted to communication with friends and strangers, sharing daily problems or gossip, as well as planning their time with friends. A part of the research group also indicated that online communication is especially useful for shy and anxious teenagers (Laghi et al., 2013). At the same time, online communication is becoming very popular among teenagers and helps them in developing self-confidence and social competencies (Borca, 2015). It turns out that young people who primarily used the Internet to build social networks and connect with friends through instant messaging are less likely to suffer from Internet-related disorders (Problematic Internet Use) in comparison to those who mainly used the Internet for non-communication purposes (Thorsteinsson \& Davey, 2014).

According to Throuvala, Griffiths, Rennoldson and Kuss (2018), this need may lie at the bottom of nomophobia, and therefore can be responsible for the rise in compulsive use of devices with Internet access. Teenagers who communicate via instant messaging are more likely to be addicted to the Internet. Such behavior poses a threat to their mental well-being. In addition, there is also a connection between mental health and the use of instant messengers. People who prefer online communication with their partners show lower interpersonal competencies (Nesi et al., 2017). Moreover, it has been observed that some 
people who use online communication more often than its direct version, have problems with emotion control and interpersonal relationships (Hormes et al., 2015). Moreover, the habitual use of this form of communication can lead to addictive behavior. It is often referred to as addiction to SNS, pathological use of SNS, as well as Facebook addiction or addiction to smartphones (Griffiths et al., 2014; Choi et al., 2015; Wegmann et al., 2015). All of these terms refer to the misuse of online communication, social networks or other social networking services (Casale et al., 2015). Communication and contact with others are the most important aspects of these technologies, regardless of their particular roles. Loneliness, social impairment, malaise, and degradation of interpersonal relationships are some of the detrimental effects of Internet abuse. Furthermore, issues with emotional regulation can also arise. (Andreassen \& Pallesen, 2014; Hormes et al., 2015). Owing to the popularity of the Internet, the youth tend to form online relationships with strangers, what is putting them at risk of cyberbullying or solicitation (Valkenburg, Peter, 2011). These phenomena, which include repetitive and violent behaviors, are inseparable elements of online communication. These actions are deliberately aimed at people who are unable to defend themselves (Kowalski et al., 2014). Research conducted by Barlet and Coyne (2014) implies that cyberbullying is relatively common among teenagers. Moreover, the authors proved that the occurrence of this phenomenon is diversified. Women tend to become cyber harassers in early adolescence, while men's tendency to cyberbullying appears later. The most common victims of cyberbullying are teenagers (Tokunaga, 2010). What is more, Fest and Qandt (2016) discovered that communication plays a significant role in the process of cyberbullying. Teenagers are exposed to this kind of danger from the beginning of adolescence. Using phones in public places has become a natural phenomenon repeated on a daily basis in order to entertain themselves and fill up the time.

\section{Entertainment and education on the Internet}

It is very common to have the computer with unlimited access to the Internet and treat these inventions as tools for entertainment and education. Any use of the Internet brings both positive and negative consequences. Baños, et al. (2017) carried out research that aimed to introduce positive psychological interventions to improve well-being among adolescents. The study was conducted using social media (Facebook), electronic mail, and other text message reminders. Even though some groups participated in their research study entirely online, the intervention proved to be highly effective. On the basis of the positive consequences of the intervention, the conducted study clearly indicates that the Internet's indisputable strength is powerful communication. It contributed to the observation of reduced levels of anxiety and depression, as well as a better overall sense of well-being. It has been suggested that playing computer games at a young age deteriorates the quality of 
making friendships and romantic relationships (Young, Yue \& Ying, 2011). Owing to this, an increasing number of young people are unable to build meaningful relationships through direct contact. It is generally believed that adolescents feel more and more confident when entering the virtual world and spend in cyberspace a lot of time. Consequently, this pattern of behavior leads to instances of Internet abuse and disorders concerning the development of social skills and lack of behavioral regulation. Furthermore, experiencing negative emotions and problematic situations from everyday life is the reason for escaping in the virtual world (Gencer \& Koc, 2012; Watts, Wagner, Velasquez \& Behrens, 2017).

Computer games are frequently referred to as a form of online entertainment. Games and the pursuit of pleasure out of gaming may conduce to the negligence of relationships, school, work duties, or other responsibilities (Kuss \& Gryffiths, 2012). Computer games can therefore be conceptualized as a continuum. Games can be described as a pleasant activity, but also constitute a pathological and even addicting form of entertainment. Since the first commercial of a video game debuted on the market in the early 1970s, Internet Gaming Disorder (IGD) has been in the spotlight of research attention. The abovementioned affliction has gained popularity as a result of several incidents concerning game-related violence (for instance, the massacre committed by James Holmes in Colorado) (Fam, 2018). Thus, IGD in adolescents is potentially driven by dysfunction of the control system and the approach system rather than the avoidance system, supporting the neurobiological model of adolescent development (Li et al.,

2019). Higher psychopathological burden, stronger hyperactivity/inattention, weaker family functioning, and poorer school performance were significantly correlated with both adolescent and parental ratings of IGD. (Wartberg et al., 2019). It turns out that strained parent-child relationships are linked to a pathological desire to play violent video games. Researchers underline that paternity support can protect teenagers against these kinds of problems. Therefore, to fight these issues effectively, preventive programs should involve paternal care and support (Schneider et al., 2017).

Regardless of threats connected with the Internet, the online world has also multiple benefits. The Internet is perceived by young people as a helpful tool in acquiring knowledge, propagation of culture, and sharing experience (Subrahmanyam \& Smahel, 2012). Cyberspace also enables the fast exchange of information, thus it may be considered as an educational tool. The Internet has become a space where the teaching and learning processes of young people intertwine (Walter, 2012; Vanden Abeele, 2016). Multiple studies conducted on a group of American teenagers show that learning and gaining knowledge constitute one of the most common reasons for using the Internet (Subrahmanyam \& Smahel, 2012). More than $60 \%$ of the surveyed teens declared that the Internet is a very important and helpful source of information for doing homework, reading compulsory books and research papers. 
Students treat the Internet as the only tool that enables finding information and gaining knowledge on topics of their interests. Over $50 \%$ of respondents believe that the content found on the Internet is reliable and there is no need to double-check facts (Dunahee \& Lebo, 2016).

Owing to easy access to learning materials and information on any topic, the Internet inevitably allows obtaining information in any foreign language. What is more, online dictionaries facilitate a more accurate understanding of foreign words. All of these aspects reduce the popularity of other ways of searching for information, such as using libraries. Consequently, the Internet becomes increasingly attractive and convenient way to obtain knowledge and learning new skills (Nair \& Saraswathy, 2017).

In conclusion, young people need a safe and stimulating environment that is both engaging and interesting (Kowalski et al., 2014). Young people reach for new technologies and takes advantage of the opportunities offered by the Internet. They spend more and more time on social media, playing online games, and using mobile applications without adult supervision (Nair \& Saraswathy, 2017). New technologies, such as artificial intelligence, as well as augmented and virtual reality, change the way adolescents interact socially (Valkenburg \& Peter, 2011). The Internet offers a variety of ways to communicate with each other and acquire information. The web also constitutes a source of creative solutions and entertainment. At the same time, it poses risk for the teenagers who build their own identities. The youth may be exposed to harmful content and behaviors, such as cyberbullying, mobbing, pornography, verbal violence, manipulation, and even extortion (Fest \& Qandt, 2016). To prevent negative consequences for their cognitive, social and emotional development, effective methods are crucial.

Teaching adolescents how to use the web in a controlled manner is an essential component of overall Internet security.

\section{Summary}

Teenagers often use the Internet for entertainment purposes as well as educational reasons (Kamieniecki \& Bochenek, 2017). They use an increasing number of online tools to present themselves to others, and their social media image is one of the most important elements of functioning on the web. Almost every respondent claims to spend multiple hours a day on the Internet, and what is even more interesting, the amount of time spent on the Internet extends more and more each year (Bochenek \& Lange, 2019). Unfortunately, apart from the wide range of positive effects of using the Internet, adolescents are exposed to many drawbacks that may be reflected in their lives. Since the history of psychological research on this issue is relatively short, it is difficult to assess to what extent this impact can be destructive. The results of the presented studies show that the Internet is extremely 
influential and supports the argument that virtual life is just as important as real life. Young people should use the Internet moderately and remember that it cannot substitute real-life relationships.

How to increase beneficial aspects of the Internet and, simultaneously, mitigate the negative consequences of Internet abuse? This issue represents a challenge for the researchers and remains unsolved to this day.

\section{Bibliography:}

Anderson, E.L., Steen, E., \& Stavropoulos, V. (2017). Internet use and problematic Internet use: A systematic review of longitudinal research trends in adolescence and emergent adulthood, International Journal of Adolescence and Youth, 4 (22), 430-454.

Andreassen, C.S., \& Pallesen, S. (2014). Social network site addiction: a comprehensive review, Current Pharmaceutical Design, 20, 4053-4061.

Baños, R.M., Etchemendy, E., Mira, A., Riva, G., Gaggioli, A., \& Botella, C. (2017). Online positive interventions to promote wellbeing and resilience in the adolescent population: A narrative review, Frontiers in Psychiatry, 8, doi: https://doi.org/10.3389/fpsyt. 2017.00010.

Barlett, C.P., \& Coyne, S.M. (2014). Meta-analysis of sex differences in cyber-bullying behavior: The moderating role of age, Aggressive Behavior, 40, 474-488.

Best, P., Manktelow, R., \& Taylor, B. (2014). Online communication, social media and adolescent wellbeing: A systematic narrative review, Children and Youth Services Review, 41, 27-36.

Bochenek, M., Lange R.(2019). Nastolatki 3.0 - raport z ogólnopolskiego badania uczniów, Warszawa: Instytut badawczy NASK.

Borca, G. \& Bina, M. \& Keller, P.S., Gilbert, L.R., Begotti, T. (2015). Internet use and developmental tasks: Adolescents' point of view, Computers in Human Behavior, 52, 49-58, doi: https://doi.org/10.1016/j.chb.2015.05.029.

Casale, S., Fioravanti, G., Flett, G.L., \& Hewitt, P.L. (2015). Self-presentation styles and problematic use of Internet communicative services: the role of the concerns over behavioral displays of imperfection, Personal Individual Differences, 76, 187-192.

Choi, S.-W., Kim, D.J., Choi, J.S., Choi, E.J., Song, W.Y., \& Kim, S., (2015). Comparison of risk and protective factors associated with smartphone addiction and Internet addiction. Journal Behaviour Addictions, 4, 308-314.

Dunahee, M., \& Lebo, H. (2016). The World Internet Project International Report (Sixth Ed.) za: http://www.digitalcenter.org/wp-content/uploads/2013/06/2015-WorldInternet-Report.pdf. 
Ekström, M., Olsson, T.,\& Shehata, A. (2014). Spaces for public orientation? Longitudinal effects of Internet use in adolescence, Information, doi: https://doi.org/17. 0.1080/1369118X.2013.862288.

Fam, J.Y. (2018). Prevalence of internet gaming disorder in adolescents: A meta-analysis across three decades, Scandinavian Journal of Psychology, 5 (59), 524-531.

Fest, R., \& Quandt, T. (2016). The Role of Online Communication in Long-Term Cyberbullying Involvement Among Girls and Boys, Journal Youth Adolescence, doi: https://doi.org/10.1007/s10964-016-0552-9.

Gencer S.,L., Koc M. (2012). Internet abuse among Teenagers and Its Relations to Internet Usage Patterns and Edmographics, Educational Technology and Societ, 2 (15), 25-36.

Griffiths, M.D., Kuss, D.J., \& Demetrovics, Z. (2014). Social networking addiction: an overview of preliminary findings, (in:) K. Feder, P. Rosenberg, and L. Curtiss (eds.), Behavioral Addictions, 119-141, San Diego: Academic Press.

Haferkamp, N., \& Krämer, N.C. (2010). Creating a digital self: impression management and impression formation on social networking sites, (in:) K. Drotner, K.C. Schrøder (eds.), Digital content creation: creativity, competence, critique, 129-149, New York: Peter Lang.

Haferkamp, N., \& Krämer N.C. (2011). Online Self-Presentation: Balancing Privacy Concerns and Impression Construction on Social Networking Sites, Privacy Online, 127-141.

Hormes, J.M., Kearns, B., \& Timko, C.A. (2015). Craving Facebook? Behavioral addiction to online social networking and its association with emotion regulation deficits, Addiction, 109, 2079-2088.

Kowalski, R.M., Giumetti, G.W., Schroeder, A.N., \& Lattanner, M.R. (2014). A meta-analysis of factors predicting cyberbullying perpetration and victimization: From the social cognitive and media effects approach, Psychological Bulletin, 4 (140), 1073-1137.

Kuss, D.J., \& Griffiths, M.D. (2012). Internet gaming addiction: a systematic review of empirical research, International Journal of Mental Health and Addiction, 10, 278-96.

Laghi, F., Schneider, B. H., Vitoroulis, I., Coplan, R. J., Baiocco, R., \& Amichai- Hamburger, Y. (2013). Knowing when not to use the Internet: Shyness and adolescents' on-line and off-line interactions with friends, Computers in Human Behavior, 1 (29), 51-57.

Li, Q., Wang, Y., Yang, Z., Dai, W., Zheng, Y., Yuwei, S., \& Liu, X. (2019). Dysfunctional cognitive control and reward processing in adolescents with Internet gaming disorder, Psychophysiology, 57, doi: https://doi.org/10.1111/psyp.13469. 
Marengo, D., Longobardi, C., Fabris, M.A., \& Settan, M. (2018). Highly-visual social media and internalizing symptoms in adolescence: The mediating role of body image concerns, Computers in Human Behavior, 82, 63-69.

Meier, E.P., \& Gray. J. (2014). Facebook photo activity associated with body image disturbance in adolescent girls, Cyberpsychology, Behavior, and Social Networking, 4 (17), 199-206, doi: https://doi.org/10.1089/cyber.2013.0305.

Mikami, A.E., Szwedo, D.E., Ahmad, S.I., Samuels, A.S., \& Hinshaw, S.P. (2015). Online Social Communication Patterns among Young Adult Women with Histories of Childhood Attention-Deficit/ Hyperactivity Disorder, Journal Abnormal Psychology, 3 (124), 576-588.

Mulgrew, K.E., Volcevski-Kostas, D., \& Rendell. P.G. (2014). The Effect of Music Video Clips on Adolescent Boys' Body Image, Mood, and Schema Activation, Journal of Youth and Adolescence, 1 (43), 92-103.

Nair, A., \& Saraswathy,S. (2017). Role of Internet in Education of Commerce Students, International Journal of Management, It E Engineering, 1 (7).

Nesi, J., Widman, L., Choukas-Bradley, S., \& Prinstein, M.J. (2017). Technology-Based Communication and the Development of Interpersonal Competencies Within Adolescent Romantic Relationships: A Preliminary Investigation, Journal of Research on Adolescence, 2 (27), 471-477.

Nowak, K.L., \& Gomes, S. B. (2014). The choices people make: the types of buddy icons people select for self-presentation online, AI E SOCIETY, 4 (29), 485-495.

Oberst, U., Wegmann, E., Stodt, B., Brand, M. \& Chamarro, A. (2017). Negative consequences from heavy social networking in adolescents: The mediating role of fear of missing out, Journal of Adolescence, 55, 51-60, doi:

https://doi.org/10.1016/j.adolescence.2016.12.008.

Oosten, J.M.F., Peter, J., \& Boot, I. (2015). Exploring Associations Between Exposure to Sexy Online Self-Presentations and Adolescents' Sexual Attitudes and Behavior, Journal of Youth and Adolescence, 5 (44), 1078-1091.

Palmqvist, R., \& Santavirta, N. (2011). What Friends are for: The Relationships Between Body Image, Substance Use, and Peer Influence Among Finnish Adolescents, Journal of Youth and Adolescence, 2 (35), 192-206.

Pantic, I. (2014). Online Social Networking and Mental Health, Cyberpsychology, Behavior, and Social Networking, doi: https://doi.org/17. 10.1089/cyber.2014.0070.

Purcell, K. (2013). 10 things to know about how teens use technology. Pew Research Center's Internet and American Life Project, za:

http:/ / www.pewinternet.org/2013/07/10/10-things-to-know-abouthow-teensuse-technology/ (dostęp: 1.10.2021). 
Rodgers, R.F., Melioli, T., Laconi, S., Bui, E., \& Chabrol, H. (2013). Internet Addiction Symptoms, Disordered Eating, and Body Image Avoidance, Cyberpsychology, Behavior, and Social Networking, 1 (16).

Schneider, L.A., King, D.L., \& Delfabbro, P.H. (2017). Family factors in adolescent problematic Internet gaming: A systematic review, Journal of Behavioral Addictions, 3 (6), 321-333.

Subrahmanyam, K., Smahel, D. (2011). Digital Youth: The Role of Media in Development, doi: https://doi.org/10.1007/978-1-4419-6278-2.

Thorsteinsson, E.B., \& Davey, L. (2014). Adolescents' compulsive Internet use and depression: A longitudinal study. Open Journal of Depression, 3, 13-17, doi: https://doi.org/10.4236/ojd.2014.31005.

Tiggemann, M. (2013). NetGirls: The Internet, Facebook, and body image concern in adolescent girls, International Journal of Eating Disorders, 2 (6), 630-633.

Throuvala, M., Griffiths, M., Rennoldson, M., Kuss, D. (2018). Motivational processes and dysfunctional mechanisms of social media use among adolescents: A qualitative focus group study, Computers in Human Behavior, doi: https://doi.org/93. 10.1016/j.chb.2018.12.012.

Tokunaga, R.S. (2010). Following you home from school: A critical review and synthesis of research on cyberbullying victimization, Computers in Human Behavior, 3 (26), 277287.

Trekels, J., Karsay, K., Eggermont, S., Vandenbosch, S. (2018). How Social and Mass Media Relate to Youth's Self-Sexualization: Taking a Cross-National Perspective on Rewarded Appearance Ideals, Journal of Youth and Adolescence, 7 (47), 1440-1455.

Tzavela, E.C., Karakitsou, C., Dreier, M., Mavromati, F., Wölfling, K., Halapi, E. (2015). Processes discriminating adaptive and maladaptive Internet use among European adolescents highly engaged online, Journal of Adolescence, 40, 34-47.

Uhls, Y.T., Ellison, N. B., \& Subrahmanyam, K. (2017). Benefits and Costs of Social Media in Adolescence, Pediatrics, 2 (140).

Vanden Abeele, M. M. (2016). Mobile youth culture: a conceptual development, Mob Media Communication, 1 (4), 85-101.

Valkenburg P. M, \& Peter J. (2011). Online Communication Among Adolescents: An Integrated Model of Its Attraction, Opportunities, and Risks, Journal of Adolescent Health, 48, 121-127.

Villani, D., Gatti, E., Confalonieri, E., Riva, G. (2012). Am I My Avatar? A Tool to Investigate Virtual Body Image Representation in Adolescence, Cyberpsychology, Behavior, and Social Networking, 8 (15). 
Vries, D.A., Peter, J., \& Graaf, H. (2016). Peter Nikken Adolescents' Social Network Site Use, Peer Appearance-Related Feedback, and Body Dissatisfaction: Testing a Mediation Model, Journal of Youth and Adolescence, 1 (45), 211-224.

Walter, N. (2012). Obszary edukacyjnych zastosowan' Internetu [Areas of Educational Applications of the Internet], Studia Edukacyjne, 23, 217-228.

Wartberg, L., Zieglmeier, M., Kammerl, R. (2019). Accordance of adolescent and parental ratings of Internet gaming disorder and their associations with psychosocial aspects, Cyberpsychology, Behavior and Social Networking, 4 (22), 264-270.

Watts L., Wagner J., Velasquez B., Behrens P.I. (2017). Cyberbullying in higher education: A literature review, Computers in Human Behavior, 69, 268-274.

Wegmann, E., Brand, M. (2016). Internet-Communication Disorder: It's a Matter of Social Aspects, Coping, and Internet-Use Expectancies, Frontiers Psychology, 7 (1747), 1-13.

Xie, X., Wang, X., Zhao, F., Lei, L., Niu, G., \& Wang, P. (2018). Online Real-Self Presentation and Depression among Chinese Teens: Mediating Role of Social Support and Moderating Role of Dispositional Optimism, Child Indicators Research, 5 (11), 15311544.

Yang, C., \& Brown, B. (2016). Online Self-Presentation on Facebook and Self Development During the College Transition, Journal of Youth and Adolescence, 2 (45), 402-416.

Young, K., Yue, X.D., \& Ying, L. (2011). Prevalence estimates and etiologic models of Internet addiction, (in:) K. Young, C.N. de Abreu (eds.), Internet addiction. A handbook and guide to evaluation and treatment, 3-18, New Jersey: John Wiley \& Sons, Inc., Hoboken. 